\title{
Effect of Helicobacter pylori infection and its eradication on cell proliferation, DNA status, and oncogene expression in patients with chronic gastritis
}

G Nardone, S Staibano, A Rocco, E Mezza, F P D'Armiento, L Insabato, A Coppola, G Salvatore, A Lucariello, N Figura, G De Rosa, G Budillon

\begin{abstract}
Background-Helicobacter pylori, the main cause of chronic gastritis, is a class I gastric carcinogen. Chronic gastritis progresses to cancer through atrophy, metaplasia, and dysplasia. Precancerous phenotypic expression is generally associated with acquired genomic instability.

Aim-To evaluate the effect of $H$ pylori infection and its eradication on gastric histology, cell proliferation, DNA status, and oncogene expression.
\end{abstract}

Methods/Subjects-Morphometric and immunohistochemical techniques were used to examine gastric mucosal biopsy specimens from eight controls, 10 patients with $H$ pylori negative chronic gastritis, 53 with $H$ pylori positive chronic gastritis, and 11 with gastric cancer.

Results-All patients with chronic gastritis were in a hyperproliferative state related to mucosal inflammation, regardless of $\boldsymbol{H}$ pylori infection. Atrophy was present in three of 10 patients with $H$ pylori negative chronic gastritis and in $\mathbf{2 6}$ of 53 with $\boldsymbol{H}$ pylori positive chronic gastritis, associated in 18 with intestinal metaplasia. DNA content was abnormal in only 11 patients with atrophy and $H$ pylori infection; eight of these also had c-Myc expression, associated in six cases with p53 expression. Fifty three patients with $H$ pylori positive chronic gastritis were monitored for 12 months after antibiotic treatment: three dropped out; infection was eradicated in 45 , in whom cell proliferation decreased in parallel with the reduction in gastritis activity; atrophy previously detected in $21 / 45$ disappeared in five, regressed from moderate to mild in nine, and remained unchanged in seven; complete metaplasia disappeared in $4 / 14$, and markers of genomic instability disappeared where previously present. In the five patients in whom $H$ pylori persisted, atrophy, metaplasia, dysplasia, and markers of genomic instability remained unchanged.

Conclusions-Chronic $H$ pylori infection seems to be responsible for genomic instability in a subset of cases of $\boldsymbol{H}$ pylori positive chronic atrophic gastritis; eradication of $\boldsymbol{H}$ pylori infection can reverse inflammation and the related atrophy, metaplasia, and genomic instability.

(Gut 1999;44:789-799)
Keywords: H pylori infection; atrophic gastritis; genomic instability; eradication therapy

Helicobacter pylori, the main cause of chronic gastric disorders, has been defined as a class I gastric carcinogen. ${ }^{1}$ However, only a minority of $H$ pylori positive patients with chronic gastritis develop gastric cancer, and the link between $H$ pylori and gastric carcinoma is unclear. $^{2}$

Gastric carcinogenesis is a multistep process progressing from chronic gastritis through glandular atrophy, metaplasia, and dysplasia..$^{3-6}$ Atrophic gastritis and intestinal metaplasia may be the long term consequences of $H$ pylori infection, ${ }^{78}$ but it is debatable whether or not bacterial eradication reverses these lesions. ${ }^{9-12}$ Acquired genomic instability, which is typical of the phenotypic expression of precancerous lesions, generally precedes neoplastic clonal expansion. ${ }^{13}{ }^{14}$

Chronic $H$ pylori infection damages gastric barrier function ${ }^{15}{ }^{16}$ and stimulates gastric cell proliferation, ${ }^{37-22}$ which leads to mucosal repair, ${ }^{22}{ }^{23}$ but which can also induce cellular DNA damage. ${ }^{3}$ 17-22 2425 The most frequent epiphenomenon of DNA alteration is activation of oncogenes and/or mutation of oncosuppressor genes. ${ }^{26-29}$ The role of these genes has been studied in colon carcinogenesis ${ }^{30-34}$ and, to a lesser extent, in gastric carcinogenesis, ${ }^{34-39}$ but their interrelation with $H$ pylori infection has yet to be defined. The aim of our study was to detect the relation between $H$ pylori infection and gastric carcinogenesis evaluated as the appearance of genomic instability and the associated phenotypic expression. To this aim we investigated gastric histology, cell proliferation, DNA content, and bcl-2, p53, and c-Myc expression in patients with chronic gastritis with and without $H$ pylori infection and after $H$ pylori eradication therapy.

Materials and methods

SUBJECTS

The study population consisted of 82 subjects (52 men and 30 women, age range $24-75$ years). They were consecutively recruited from 1 January 1995 to 30 June 1995 from a population of 680 subjects referred to our department for dyspepsia according to the following

Abbreviations used in this paper: PCNA, proliferating cell nuclear antigen; AgNOR, nucleolar organiser region. 
Table 1 Frequency of clinical, histological and immunohistochemical variables in the population studied

\begin{tabular}{|c|c|c|c|c|c|c|c|c|c|c|c|c|c|}
\hline & $\begin{array}{l}\text { No of } \\
\text { (subjects) }\end{array}$ & Age (y) & $\begin{array}{l}\text { Sex } \\
\text { (\% men) }\end{array}$ & $\begin{array}{l}\text { Erosion/ } \\
\text { ulcer }\end{array}$ & $P M N$ & $\begin{array}{l}\text { Lymphocytes/ } \\
\text { monocytes }\end{array}$ & Atrophy & $I M$ & Dysplasia & $\begin{array}{l}\text { DNA } \\
\text { aneuploidy }\end{array}$ & $p 53$ & $b c l-2$ & $c-M y c$ \\
\hline Controls & 8 & $35(10)$ & 37 & - & - & - & - & - & - & - & - & 100 & - \\
\hline $\mathrm{nCG}$ & 10 & $44(11)$ & 50 & 30 & - & ++ & 30 & 10 & - & - & - & 100 & - \\
\hline pCG & 53 & $50(11)$ & 69 & 55 & +++ & + & 49 & $34^{\star}$ & 6 & 21 & 15 & 100 & 15 \\
\hline GC & 11 & $63(7)$ & 90 & - & - & - & - & - & - & 100 & 64 & 27 & 36 \\
\hline
\end{tabular}

Values are percentages except for age which is mean (SD). nCG, H pylori negative chronic gastritis; pCG, $H$ pylori positive chronic gastritis; GC, gastric cancer; PMN, polymorphonuclear leucocytes; IM, intestinal metaplasia ( ${ }^{\star}$ total number 18: 16 complete and two incomplete).
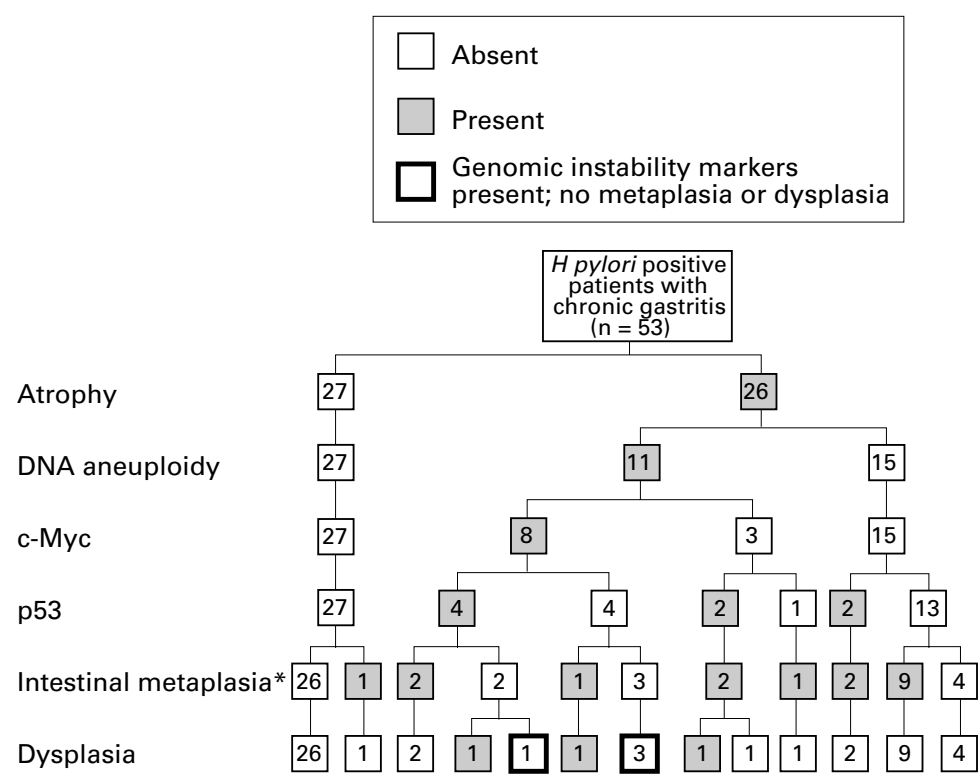

Figure 1 Distribution of histological and immunohistochemical features and DNA content in $53 \mathrm{H}$ pylori positive patients with chronic gastritis. ${ }^{\star} 16$ complete and two incomplete.

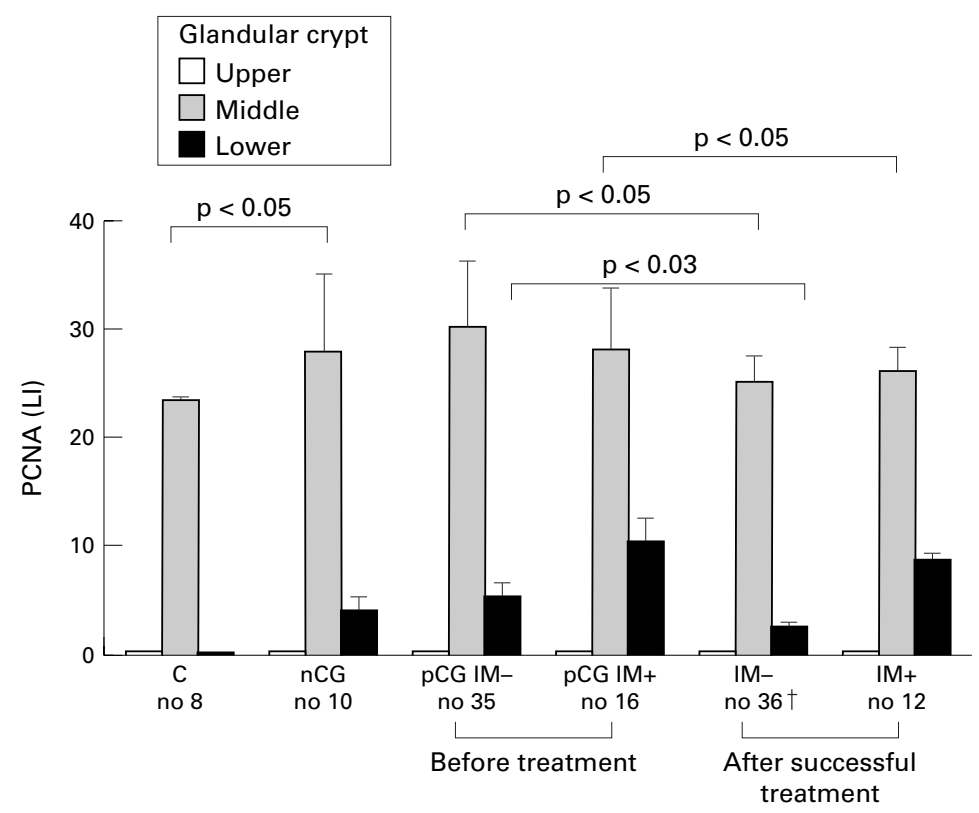

Figure 2 Immunohistochemical expression of proliferating cell nuclear antigen (PCNA) in gastric crypt sections (as indicated on the figure; a mean of five well oriented crypts for each patient) of patients with functional dyspepsia, $H$ pylori negative chronic gastritis, or $H$ pylori positive chronic gastritis, with or without complete intestinal metaplasia (IM), before and after $H$ pylori eradication. LI, labelling index, expressed as percentage of PCNA positive nuclei; $C$, controls with functional dyspepsia; $n C G, H$ pylori negative chronic gastritis; pCG IM-, H pylori positive chronic gastritis without intestinal metaplasia; $p C G$ $I M+, H$ pylori positive chronic gastritis with complete intestinal metaplasia; IM-, chronic gastritis without intestinal metaplasia after $H$ pylori eradication; IM+, chronic gastritis with intestinal metaplasia after $H$ pylori eradication. + Three patients dropped out; intestinal metaplasia disappeared in four subjects. entry criteria: no antisecretory or antibiotic drugs in the previous two months; no anticoagulant drugs in the last week; no severe associated diseases (liver, kidney, cardiovascular, etc). They were subdivided into four groups according to histological features and $H$ pylori status: eight $H$ pylor $i$ negative controls affected by functional dyspepsia with normal gastric histology; 10 patients with $H$ pylori negative chronic gastritis (nCG); 53 patients with $H$ pylori positive chronic gastritis (pCG); and 11 patients with gastric cancer (three early and eight invasive, of which five were intestinal and three diffuse types). The pCG patients were also examined 12 months after eradication therapy ( 15 days of treatment with omeprazole $20 \mathrm{mg}$ twice a day, clarithromycin $500 \mathrm{mg}$ twice a day, and tinidazole $500 \mathrm{mg}$ twice a day). $H$ pylori status was evaluated by histology and the ${ }^{13} \mathrm{C}$-urea breath test as described in the Maastricht consensus report. ${ }^{40}$ The presence of CagA protein, a marker of $H$ pylori virulence, ${ }^{41}$ was investigated only in $25 / 53$ of pCG patients. Informed consent was obtained from all subjects.

At study entry and at one year after eradication therapy, at least nine gastric biopsy specimens were taken during upper endoscopy in the body, angulus, and antrum of each subject (three from each site). For cancer patients, gastric samples were obtained from the surgical specimen. The specimens were immediately fixed in 10\% neutral buffered formalin, embedded in paraffin wax, and routinely processed. Histological, immunohistochemical, morphometric, and DNA ploidy evaluations were performed on all biopsy samples independently by two pathologists. After the independent reviews, each case was evaluated jointly and disagreements were resolved by consensus.

HISTOPATHOLOGICAL DIAGNOSIS

Haematoxylin and eosin stains were used for the histopathological diagnosis; the modified Giemsa stain was used for $H$ pylori identification. Presence of $H$ pylori, degree of inflammatory reaction and glandular atrophy, intestinal metaplasia, and cellular dysplasia were diagnosed and classified according to the updated Sydney system ${ }^{42}$ in each biopsy sample. The diagnosis of atrophy, defined as loss of glandular tissue, was based on agreement between the pathologists on at least two samples for each site investigated.

IMMUNOHISTOCHEMISTRY

For each case, $4 \mu \mathrm{m}$ thick serial sections were cut from paraffin wax blocks, mounted on acidcleaned glass slides, and heated at $55^{\circ} \mathrm{C}$ for 60 minutes. Slides were dewaxed and rehydrated, 
then the endogenous peroxidase activity was inhibited by incubation with $3 \% \quad \mathrm{H}_{2} \mathrm{O}_{2}$ in methanol (20 minutes at room temperature). To reduce non-specific background staining, slides were incubated with $5 \%$ goat serum (15 minutes at room temperature). To enhance immunostaining, sections were treated with an antigen retrieval solution $(10 \mathrm{mM}$ citric acid monohydrate, $\mathrm{pH}$ 6.0, adjusted with $2 \mathrm{M} \mathrm{NaOH}$ ) and heated three times in a microwave oven at high
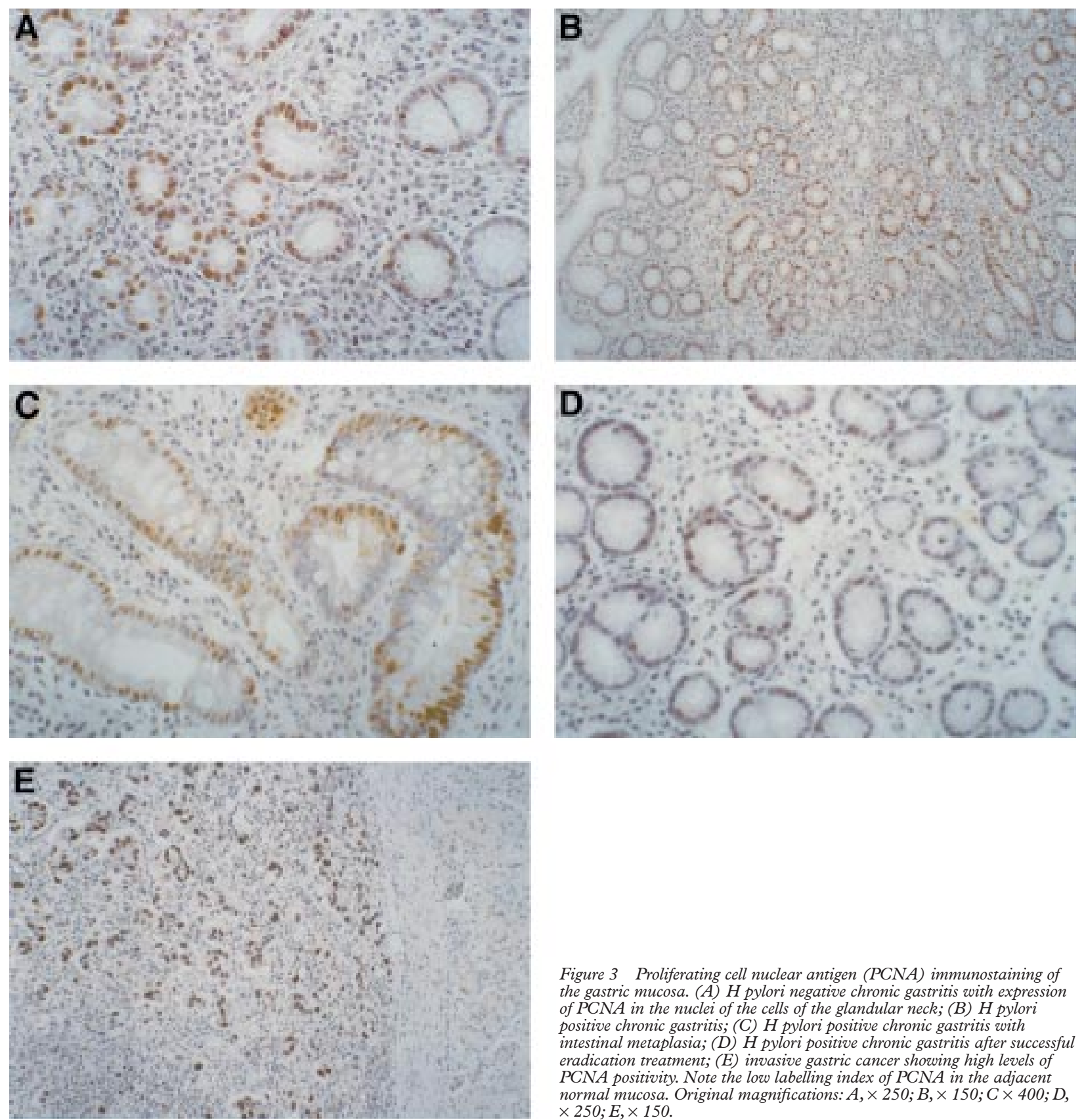

Figure 3 Proliferating cell nuclear antigen (PCNA) immunostaining of the gastric mucosa. (A) H pylori negative chronic gastritis with expression of PCNA in the nuclei of the cells of the glandular neck; (B) H pylori positive chronic gastritis; (C) H pylori positive chronic gastritis with intestinal metaplasia; (D) H pylori positive chronic gastritis after successful eradication treatment; $(E)$ invasive gastric cancer showing high levels of PCNA positivity. Note the low labelling index of PCNA in the adjacent normal mucosa. Original magnifications: $A, \times 250 ; B, \times 150 ; C \times 400 ; D$, $\times 250 ; E, \times 150$.

Table 2 Nucleolar organiser region (AgNOR) counts (number and area) in gastric crypt sections of patients with gastritis with and without Helicobacter pylori infection and gastric cancer

\begin{tabular}{|c|c|c|c|c|c|c|c|c|c|c|}
\hline \multirow[b]{3}{*}{ Diagnostic groups } & \multirow{3}{*}{$\begin{array}{l}\text { Patients } \\
(n)\end{array}$} & \multicolumn{9}{|c|}{ Crypt sections } \\
\hline & & \multicolumn{3}{|l|}{ Upper } & \multicolumn{3}{|l|}{ Middle } & \multicolumn{3}{|l|}{ Lower } \\
\hline & & Number & Area & $p$ Value & Number & Area & $p$ Value & Number & Area & $p$ Value \\
\hline Controls & 8 & $1.1(0.01)$ & $4.0(0.07)$ & \multirow{2}{*}{$<0.05$} & $1.1(0.02)$ & $4.0(0.08)$ & \multirow{4}{*}{$<0.01$} & $1.1(0.01)$ & $3.8(0.01)$ & \multirow{2}{*}{$<0.05$} \\
\hline H pylori negative gastritis & 11 & $1.1(0.70)$ & $4.3(0.10)$ & & $1.3(0.75)$ & $4.8(0.12)$ & & $1.2(0.63)$ & $4.1(0.13)$ & \\
\hline H pylori positive gastritis & 53 & $1.1(0.02)$ & $4.4(0.09)$ & \multirow{2}{*}{$<0.05$} & $1.4(0.09)$ & $4.9(0.13)$ & & $1.3(0.09)$ & $4.2(0.10)$ & \multirow{3}{*}{$<0.01$} \\
\hline $\begin{array}{l}\text { H pylori positive intestinal } \\
\text { metaplasia }\end{array}$ & 16 & $1.1(0.01)$ & $4.8(0.08)$ & & $1.4(0.01)$ & $4.8(0.09)$ & & $1.3(0.09)$ & $4.8(0.11)$ & \\
\hline Gastric cancer & 11 & & & $3(7.8)$ & & & & $15.8(2.1)$ & & \\
\hline
\end{tabular}

A mean number of five well oriented crypts was examined for each patient. Results are expressed as mean (SD) of positive cells.

$\mathrm{p}$ Value was calculated using the Mann-Whitney U test. Gastric cancer values (total rate) are reported but they were not considered in the statistical evaluation. 
power for five minutes. Finally, slides were incubated with the appropriate primary antisera in a moist chamber overnight at $4^{\circ} \mathrm{C}$. The monoclonal primary antibodies used were: anti-proliferating cell nuclear antigen (antiPCNA, PC10; DBA, Milan, Italy; dilution 1:500); anti-bcl-2 protein (Dako, Milan, Italy; dilution 1:400); anti-c-Myc protein (Oncogene Science, San Diego, California, USA; c-Myc p62, dilution 1:50); anti-p53 protein (NCL-CM1, YLEM, Rome, Italy; dilution 1:150).

Immunohistochemical staining reactions for each of the antibodies tested were compared within corresponding areas of the tissue sections from the consecutive slides. The avidin-biotin-peroxidase complex procedure (ABC standard; Vector Laboratories, Burlingame, California, USA) was then performed as described by Hsu et al. ${ }^{43}$ Peroxidase activity was detected with diaminobenzidine as substrate. Finally, sections were weakly counterstained with Harris's haematoxylin and coverslipped with a synthetic mounting medium.

Negative controls with normal human serum replacing specific primary antibodies were included in each run. Positive controls were a case of colon adenocarcinoma for $\mathrm{p} 53$ protein, a normal lymph node for c-Myc and PCNA, and a case of a low grade follicular lymphoma for bcl-2 protein. Sections were considered positively stained only in cases of unequivocal nuclear staining for p53, c-Myc, and PCNA, and cytoplasmic staining for bcl-2.

The degree of immunopositivity was evaluated semiquantitatively. A total of 300 cells was counted in random fields from representative areas of the lesions, and the immunoreactive cells were roughly assessed and expressed as percentages. The scoring system for all the antibodies tested was: 0-5\% (negative); $5-25 \%$ (low positivity); 25-50\% (moderate positivity); $>50 \%$ (high positivity).

STAINING AND COUNTING OF NUCLEOLAR

ORGANISER REGIONS (AgNORS)

For each case, a $4 \mu \mathrm{m}$ section was dewaxed in xylene and rehydrated through graded ethanol to deionised distilled water. AgNOR staining was performed as described by Egan et al. ${ }^{44}$ The final working solution was obtained by dissolving gelatin in $1 \%$ aqueous formic acid at a concentration of $2 \%$, and mixing it with a $60 \%$ aqueous silver nitrate solution $(1: 2, \mathrm{v} / \mathrm{v})$. This silver colloid solution was applied to the sections (60 minutes at room temperature, shielded from daylight). The sections were then washed with deionised distilled water, and counterstained with Mayer's haematoxylin, dehydrated, and mounted with a synthetic medium. The usual controls were performed as described by Crocker and Nar. ${ }^{45}$
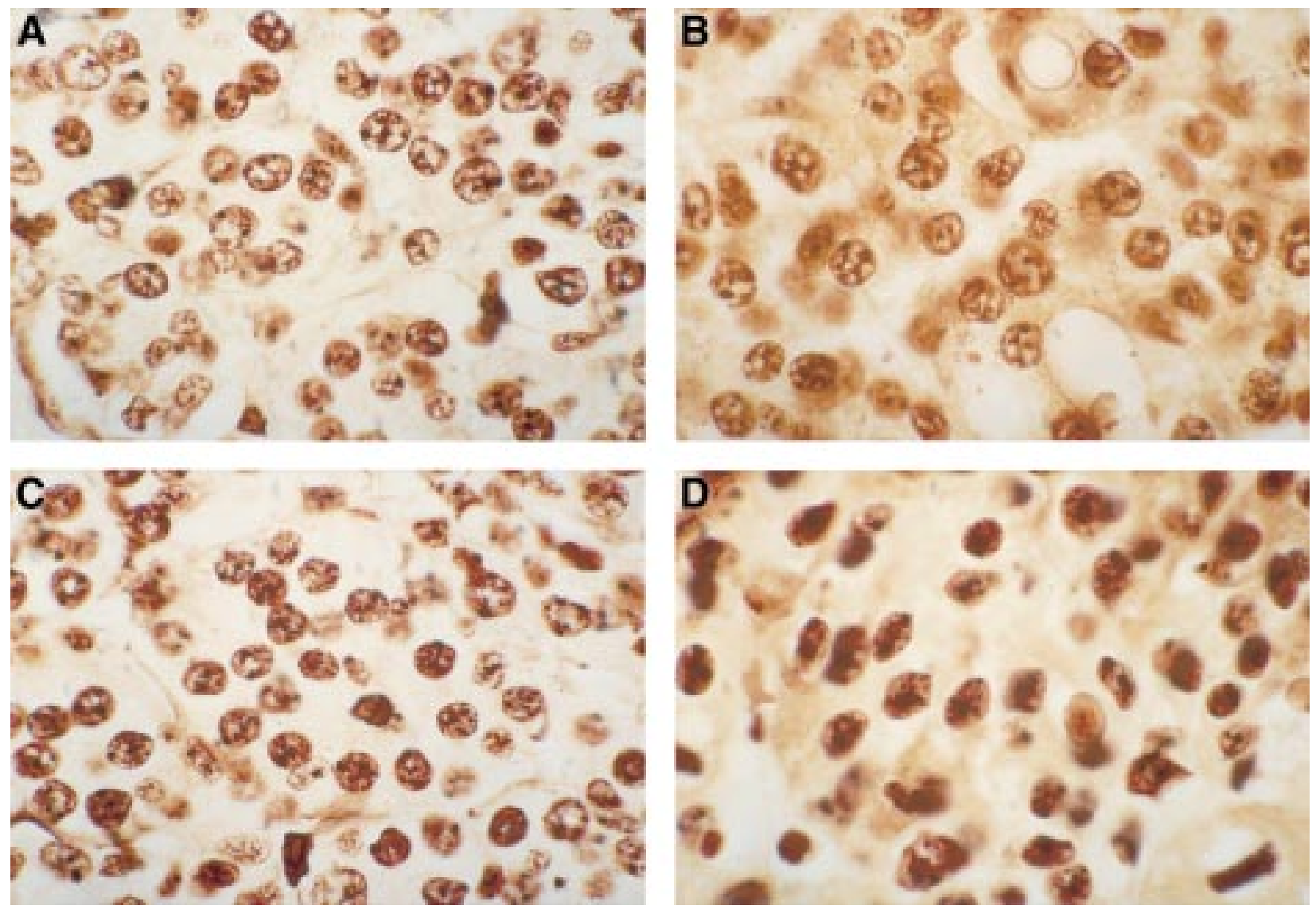

Figure 4 Silver stained nucleolar organiser regions (AgNORs) in gastric mucosa. (A) H pylori negative chronic gastritis: small to medium-sized AgNORs in the nuclei. (B) H pylori positive chronic gastritis: medium-sized irregular AgNORs in the nuclei. (C) H pylori positive chronic gastritis, after eradication treatment. (D) Gastric cancer: large, irregular and sometimes unusually shaped AgNORs in neoplastic cells. Original magnification: A, B, $C$ and $D, \times 1000$, oil immersion. 

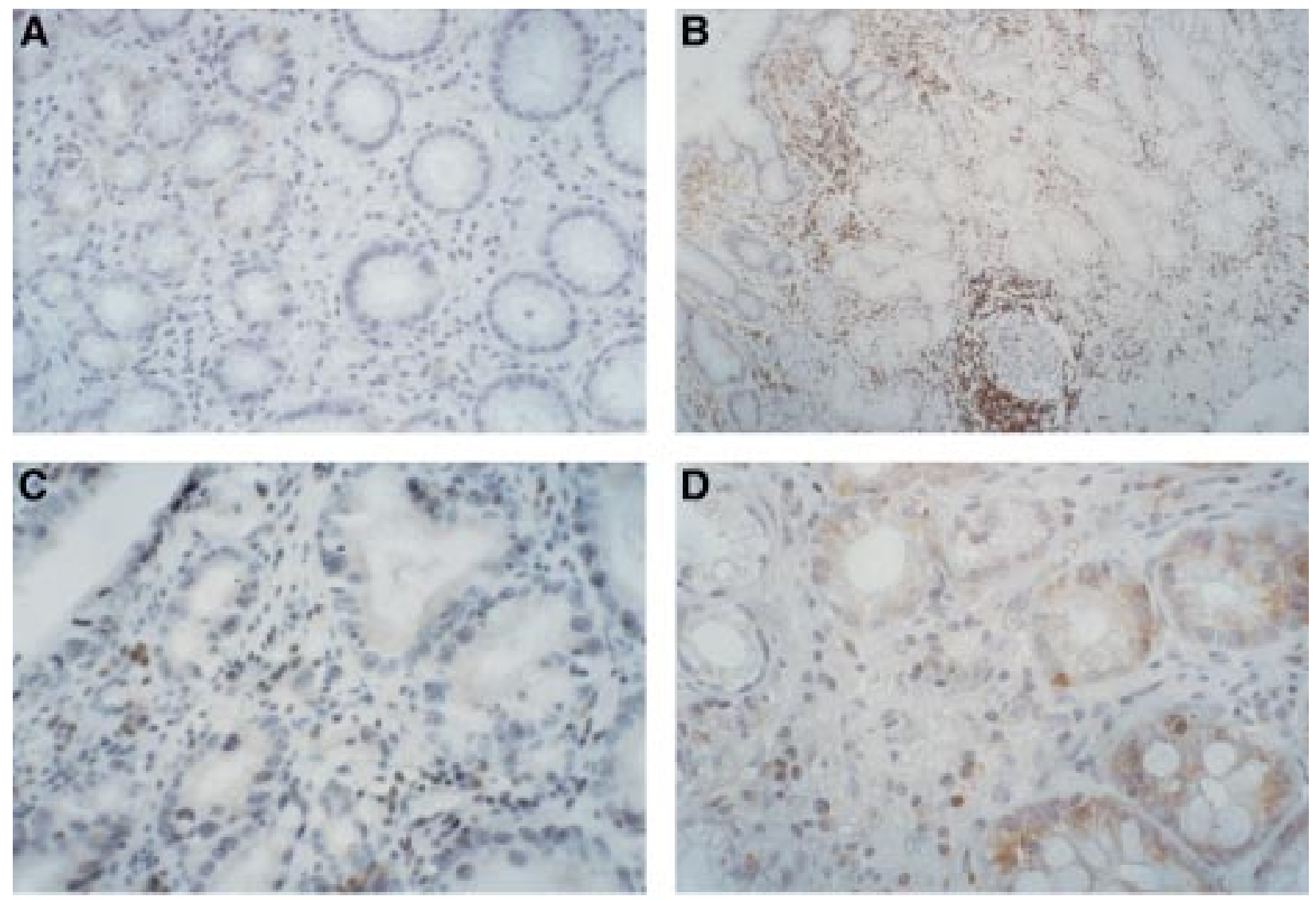



Figure 5 bcl-2 protein expression. (A) H pylori negative chronic gastritis: moderate bcl-2 expression. (B) $H$ pylori positive chronic gastritis. (C) $H$ pylori positive chronic gastritis with dysplasia: low bcl-2 expression. (D) $H$ pylori positive chronic gastritis: moderate expression of bcl-2 protein in areas of intestinal metaplasia. (E) Nodal metastasis from gastric cancer: negative for bcl-2 protein in gastric cancer cells. Original magnifications: $A, \times 250$; $B, \times 250 ; C, \times 400 ; D, \times 250 ; E, \times 100$.

MORPHOMETRIC ANALYSIS

A Leica Quantimet 500C-Image analyser and processing system was used for morphometric analysis. Images were recorded by a JVC TK-1280E videocamera, connected to a Leitz Orthoplan light microscope. A QWIN V01.00 software package elaborated the data. Within the selected fields, a final number of 200 consecutive nuclei of cells from each case were measured with $a \times 40$ lens. Image acquisition and colour detection were performed in "RGB" (an option that allows the selection of red, green, and blue). Artefacts and image overlapping were corrected in Binary Edit. The AgNOR number for each nuclear area, the area of nucleus and each AgNOR, and the total area of AgNOR were calculated automatically, as were AgNOR length, breadth, perimeter, roundness, and the aspect ratio of each nucleus. ${ }^{46}{ }^{47}$ The perimeter was rectified using a correction factor of 1.064 . Values are expressed in $\mu \mathrm{m}$.

DNA PLOIDY

The Feulgen (sulphuric acid-fucsin) technique was used for nuclear DNA staining of a section from each case, deparaffinised in xylene and rehydrated through decreasing concentrations of ethanol. Cellular DNA was quantified using a microprocessor-controlled image analysis system (Leica-Quantimet 500C analyser, a Sony Ccd camera, and a Leitz Orthoplan microscope). Leica-QWIN V0200A software was used to analyse the data. At least 200 cells from each patient were examined in non-consecutive random fields of representative areas of the lesions. The following indexes were determined for each 
A

\section{Cell Count}



B

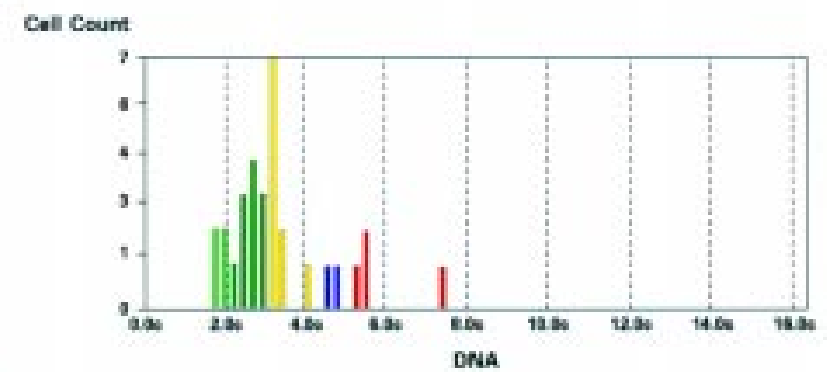

C

Coll Coumt

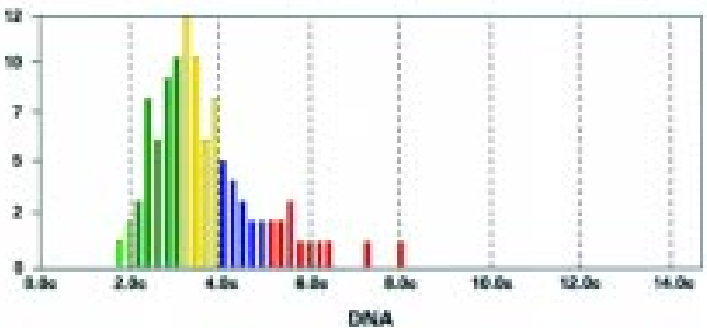

Figure 6 Representative DNA ploidy patterns in Feulgen stained sections of gastric mucosa. (A) H pylori positive chronic gastritis with moderate dysplasia: mild degree of aneuploidy. (B) H pylori positive chronic gastritis not responsive to eradication therapy without dysplasia: mild degree of aneuploidy. (C) Aneuploid pattern in gastric cancer (image analysis Quantimet 500C).

measurement: normal diploid DNA content (2c); $2 \mathrm{c}$ deviation index $(2 \mathrm{cDI})$, defined as the variance in DNA content of single cells around the normal diploid (2c) DNA peak; 5c exceeding events $(5 \mathrm{cEE})$, defined as the percentage of cells with DNA content higher than 5c; DNA malignancy grade (DNA-MG), a logarithmic transformation of the $2 \mathrm{cDI}$ value to produce a continuous scale ranging from 0 to 3.0 DNA content. ${ }^{48}$ The methodology described here has been fully validated in gastric biopsy samples. ${ }^{49}$
ANTI-CagA SERUM

The $H$ pylori strain CCUG 17874 (CagA+) was denatured in Laemmli buffer ${ }^{50}$ at $100^{\circ} \mathrm{C}$ for five minutes and electrophoresed in a $10 \%$ polyacrylamide gel with sodium dodecyl sulphate. Proteins were transferred to nitrocellulose sheets which were saturated with $3 \%$ defatted milk in phosphate buffered saline and $0.1 \%$ Triton X (Blotto). Strips were cut out, and serum samples were assayed at a dilution of 1:200 in Blotto. After overnight incubation at room temperature, strips were washed with Blotto, and then incubated with anti-human IgG conjugated with peroxidase at room temperature for 90 minutes. After washing, the reaction was visualised by addition of the substrate $\left(\mathrm{H}_{2} \mathrm{O}_{2}\right.$ in a solution of $0.3 \%$ 4-chloro-Inaphthol in $0.05 \mathrm{M}$ Tris/ $\mathrm{HCl}$ buffer, $\mathrm{pH}$ 6.8). An anti-CagA antibody raised in rabbit against a recombinant CagA fragment served as a positive control.

\section{STATISTICAL ANALYSIS}

We set the power to 0.8 , with type I error $=$ 0.05 and control to case ratio $1: 1$. The aim was to detect a minimal difference of $30 \%$ between nCG and pCG groups. Data were analysed with the SPSS package for Windows. The categorical variables (H pylori infection, cell infiltration, atrophy, intestinal metaplasia, dysplasia, DNA ploidy, p53, and c-Myc) were analysed using the $\chi^{2}$ test or Fisher's exact test. Correlation between these variables was assessed using the Spearman correlation coefficient. The non-parametric Mann-Whitney U test was used to compare the DNA values (2c, 2cDI, 5cEE, and $\mathrm{MG}$ ), AgNOR area, and PCNA expression in gastric crypt sections of patients with functional dyspepsia and gastritis with and without $H$ pylori infection. The Wilcoxon matched pair test was used to evaluate PCNA expression in gastric crypt sections of patients with gastritis with $H$ pylori infection before and after eradication therapy.

The analysis of the "before" and "after" data in the $H$ pylori positive group given eradication treatment was evaluated with the McNemar test.

\section{Results}

Table 1 shows the clinical, histological, and immunohistochemical variables of the population studied. Mean age increased in rank order from normal controls to patients with chronic gastritis and to those with gastric cancer; male sex was prevalent in $H$ pylori related disease

Table 3 Gastric mucosa DNA ploidy variables in patients with gastritis and gastric cancer

\begin{tabular}{|c|c|c|c|c|c|c|c|c|c|}
\hline \multirow[b]{2}{*}{ Diagnostic groups } & \multirow{2}{*}{$\begin{array}{l}\text { Patients } \\
\text { (n) }\end{array}$} & \multicolumn{8}{|l|}{$D N A$ indexes } \\
\hline & & $2 c$ & p Value & $2 c D I$ & p Value & $5 c E E$ & $p$ Value & $M G$ & p Value \\
\hline nCG with euploidy & 10 & $1.36(0.14)$ & NS & $0.95(0.43)$ & NS & - & & $0.49(0.14)$ & NS \\
\hline pCG with euploidy & 42 & $1.27(0.09)$ & & $0.59(0.23)$ & & - & & $0.35(0.10)$ & \\
\hline pCG with aneuploidy & 11 & $1.65(0.25)$ & $<0.0001$ & $2.46(0.98)$ & $<0.0001$ & $7.55(4.53)$ & & $0.91(0.22)$ & $<0.0001$ \\
\hline Gastric cancer & 11 & $2.26(0.98)$ & NS & $10.71(12.47)$ & $<0.05$ & $22.76(12.47)$ & NS & $1.60(0.68)$ & $<0.05$ \\
\hline
\end{tabular}

Results are expressed as mean (SD). p Value is calculated using the Mann-Whitney U test. nCG, $H$ pylori negative chronic gastritis; pCG, $H$ pylori positive chronic gastritis; $2 \mathrm{c}$, normal diploid DNA content; 2cDI, 2c deviation index; $5 \mathrm{cEE}$, 5c-exceeding event; MG, DNA malignancy grade. 
Table 4 Spearman correlation coefficient $(p<0.0001)$ of the main parameters analysed in the H pylori positive chronic gastritis group

\begin{tabular}{|c|c|c|c|c|c|c|c|c|c|c|c|}
\hline & H pylori & $P M N$ & $\begin{array}{l}\text { Lymphocytes/ } \\
\text { monocytes }\end{array}$ & Atrophy & $I M$ & Dysplasia & $\begin{array}{l}\text { DNA } \\
\text { aneuploidy }\end{array}$ & PCNA & $p 53$ & $b c l-2$ & $c-M y c$ \\
\hline H pylori & 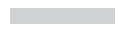 & - & - & - & - & - & - & - & - & - & - \\
\hline PMN & - & 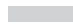 & - & - & - & - & - & - & - & - & - \\
\hline Lymphocytes/monocytes & - & - & 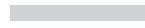 & - & - & - & - & - & - & - & - \\
\hline Atrophy & - & - & - & 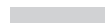 & - & - & 0.61 & - & 0.57 & - & 0.49 \\
\hline IM & - & - & - & - & 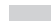 & - & - & - & - & - & - \\
\hline Dysplasia & - & - & - & - & - & D. & - & - & - & - & - \\
\hline DNA aneuploidy & - & - & - & 0.61 & - & - & - & - & 0.58 & - & 0.70 \\
\hline PCNA & - & - & - & - & - & - & - & 故 & - & - & - \\
\hline P53 & - & - & - & 0.57 & - & - & 0.58 & - & b & - & - \\
\hline bcl-2 & - & - & - & - & - & - & - & - & - & 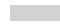 & - \\
\hline $\mathrm{c}-\mathrm{Myc}$ & - & - & - & 0.49 & - & - & 0.70 & - & - & - & 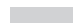 \\
\hline
\end{tabular}

PMN, polymorphonuclear leucocytes; IM, complete intestinal metaplasia; PCNA, proliferating cell nuclear antigen.

and gastric cancer. A gastric and/or duodenal erosive/ulcerative disease was detected in 30\% of $\mathrm{nCG}$ cases and $55 \%$ of pCG cases. The inflammatory infiltrate consisted of neutrophils in pCG patients and mainly lymphomonocytes in nCG. Gastric atrophy was mild in $30 \%$ of nCG subjects and was generally restricted to the antrum. Atrophy was detected in $49 \%$ (26/ 53) of pCG patients; it was mild and restricted to the antrum in five patients, and moderate,


Figure $7 \quad c-M y c$ expression. (A) H pylori positive chronic gastritis: low to moderate positivity for $c-M y c$ expression. (B) H pylori positive chronic gastritis with intestinal metaplasia: moderate degree of positivity for $c-M y c$ protein. (C) Gastric cancer: positivity for neoplastic cells for $c-M y c$ protein. Original magnifications: $A, \times 400 ; B \times 400 ; C \times$ 100. extending to the angulus, in 21 patients. Complete intestinal metaplasia, associated with atrophy, was found in $1 / 10 \mathrm{nCG}$ and $16 / 53$ pCG patients (restricted to the antrum in 10 of the latter). Incomplete metaplasia with atrophy was found in antral biopsy specimens from only $2 / 53$ pCG patients. These two patients also had an abnormal DNA content and p53 and c-Myc overexpression. Gastric dysplasia, detected in the antrum of $3 / 53$ pCG patients (one mild and two moderate), was associated with intestinal metaplasia (one complete and one incomplete), c-Myc and/or p53 overexpression in two cases, and abnormal DNA content in all three. Figure 1 gives the histological and immunohistochemical features and DNA content in pCG patients.

Cell proliferation, assessed by evaluation of PCNA expression (figs 2 and 3) and AgNOR silver staining, number, and morphometric variables, was increased (table 2 and fig 4 ) with respect to healthy controls in patients with gastritis regardless of $H$ pylori infection, and associated with the inflammation. AgNOR expression was higher (about 3- to 5-fold) in patients with gastric cancer than in the other groups (table 2). PCNA expression was 2-fold higher in the lower basal portion of the gland in $\mathrm{pCG}$ patients with intestinal metaplasia compared with pCG patients without intestinal metaplasia (fig 2).

Expression of bcl-2 was preserved in controls and the gastritis groups, regardless of $H$ pylori infection, intestinal metaplasia, and dysplasia (fig 5A-D). In gastric cancer, bcl-2 was expressed at very low levels in three early cancers and was not detectable in the remaining eight invasive cancers (fig $5 \mathrm{E}$ ).

Image analysis of DNA content showed aneuploidy in $11 / 53$ pCG patients, confined to biopsy specimens in which atrophy was present, and in all gastric cancer patients (fig 6 ). The DNA values (DNA indexes, 2cDI, $5 \mathrm{cEE}$, and $\mathrm{MG}$ ) were higher in gastric cancer than in pCG with aneuploidy (table 3). There were no significant differences in DNA values between the remaining groups (nCG with euploidy versus pCG with euploidy; table 3 ) or with regard to sex and age of patients (data not shown). Aneuploidy was significantly associated with atrophy $(11 / 11)$ and expression of p53 (6/11) and c-Myc (8/11) oncoproteins (fig 1 and table 4$)$.

The expression of c-Myc was low to moderate in $8 / 53$ pCG patients (fig 7A, B); all these 

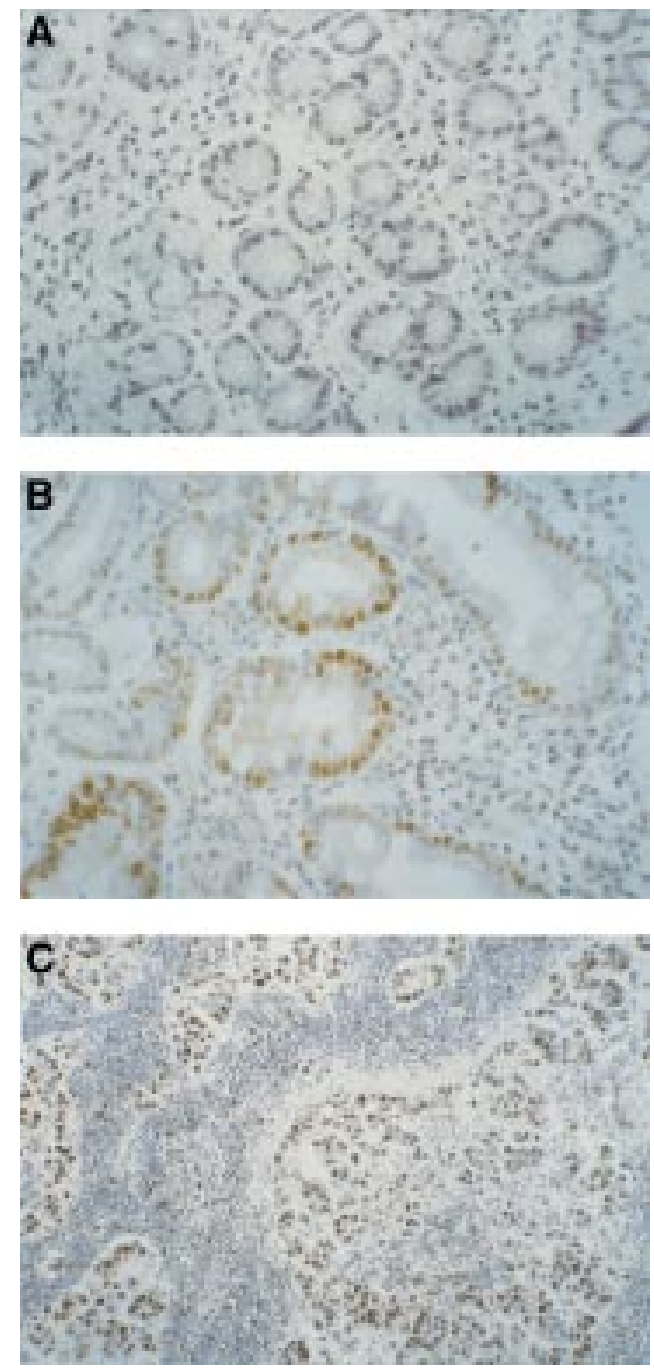

Figure 8 p53 protein expression. (A) H pylori positive chronic gastritis: sparse low positivity for $p 53$ protein. (B) $H$ pylori positive chronic gastritis with intestinal metaplasia: positivity for $p 53$ protein in areas of intestinal metaplasia. (C) Gastric cancer: high positivity for p53 protein. Original magnifications: $A, \times 250 ; B, \times 250 ; C, \times$ 100.

patients also had an abnormal DNA content, and two had glandular dysplasia (fig 1). A moderate to strong c-Myc positivity was detected in 4/11 gastric cancers (fig 7C), while c-Myc was undetectable in control subjects and $\mathrm{nCG}$ patients.

Table 5 Histological and genomic parameters in $53 \mathrm{H}$ pylori positive patients with chronic gastritis before and after eradication therapy

\begin{tabular}{lllll}
\hline & & After therapy & \\
\cline { 3 - 4 } & $\begin{array}{l}\text { Before therapy } \\
(n=53)\end{array}$ & $\begin{array}{l}\text { H pylori eradicated } \\
(n=45)\end{array}$ & $\begin{array}{l}\text { H pylori persisted } \\
(n=5)\end{array}$ & p Value \\
\hline Atrophy & $26(49)$ & $16(35)$ & $5(100)$ & NS \\
Intestinal metaplasia & $18^{\star}(34)$ & $10(22)$ & $4 \dagger(80)$ & NS \\
Dysplasia & $3(6)$ & 0 & $3(60)$ & NS \\
DNA aneuploidy & $11(21)$ & 0 & $3(60)$ & 0.01 \\
p53 & $8(15)$ & 0 & $2(40)$ & 0.05 \\
c-Myc & $8(15)$ & 0 & $3(60)$ & 0.05
\end{tabular}

Values in parentheses are percentages. $p$ Value was calculated using the McNemar test comparing before and after therapy regardless of the outcome of treatment. The eradication treatment consisted of 15 days on omeprazole $20 \mathrm{mg}$ twice a day, clarithromycin $500 \mathrm{mg}$ twice a day, and tinidazole $500 \mathrm{mg}$ twice a day. Three subjects dropped out during follow up.

$\star 16$ complete and two incomplete intestinal metaplasias; †two complete plus two incomplete intestinal metaplasias.
Finally, p53 was overexpressed in $63 \%$ (7/11) of gastric cancers (fig 8C) and in 15\% (8/53) of pCG (fig $8 \mathrm{~A}, \mathrm{~B})$; six of the latter also had abnormal DNA content and gastric metaplasia (fig 1). No control subject nor nCG patient showed p53 expression.

The frequency of DNA aneuploidy, and p53 and c-Myc expression in relation to histological findings shows that aneuploidy and p53 and c-Myc expression were invariably associated with atrophy and were more pronounced in patients with intestinal metaplasia (fig 1).

The $H$ pylori CagA status, investigated in $25 / 53$ patients, was positive in 22 and negative in three. Atrophy was present in $54 \%$ of the CagA positive patients, intestinal metaplasia in $36 \%$, dysplasia in $4 \%$, DNA aneuploidy in $22 \%$, and c-Myc and p53 expression in $22 \%$ and $18 \%$ respectively. However, the small number of subjects with CagA negative $H$ pylori prevented statistical evaluation.

One year after antibiotic treatment, the study protocol was repeated in the 53 pCG patients (table 5). Three patients dropped out. H pylori was eradicated in $90 \%$ of patients $(45 / 50)$, in whom cell proliferation, PCNA expression (fig $3 \mathrm{E}$ ) and AgNOR staining (fig 4C) decreased in parallel with the reduction in inflammatory infiltrate, whereas no significant difference was detected in patients with intestinal metaplasia (fig 2). The intensity of neutrophil infiltration was directly related to the rate of mucosal cell proliferation in the patients who were responsive to $H$ pylori eradication treatment $(\mathrm{p}<0.02)$. Atrophy disappeared completely in five patients (all with mild atrophy restricted to the antrum); it regressed from moderate to mild only in the antrum in nine and remained unchanged in seven. Complete metaplasia associated with atrophy disappeared in four of 14 patients. Finally, DNA aneuploidy and p53 and $\mathrm{c}-\mathrm{Myc}$ expression, previously detected in eight, six, and five of the 45 patients respectively, disappeared.

In the five subjects in whom $H$ pylori infection persisted after eradication therapy, atrophy, metaplasia, dysplasia, and markers of genomic instability remained unchanged.

\section{Discussion}

Concurrent or previous $H$ pylori infection is associated with a 2.7- to 12-fold risk of gastric cancer. ${ }^{2}$ Carcinogenesis invariably starts with cell hyperproliferation. ${ }^{2}{ }^{35152}$ The relation between $H$ pylori infection, gastric mucosal damage, and the cell proliferation rate is a matter of debate. $H$ pylori urease activity and leucocyte infiltration have a mitogenic effect, ${ }^{3}{ }^{19}{ }^{53-55}$ but gastric cell hyperproliferation also occurs independently of $H$ pylori infection. ${ }^{56}{ }^{57}$ In our study, the gastric epithelial proliferative rate, evaluated using PCNA and AgNOR analyses, was increased in gastric cancer and chronic gastritis, regardless of $H$ pylori infection (figs 2-4 and table 2). Therefore mucosal cell hyperproliferation appears to be a constant finding of chronic gastric damage whatever the aetiology, but it is related to inflammatory infiltrates which were prevalently lympho-monocytic in $\mathrm{nCG}$ and made up of 
polymorphonuclear leucocytes in pCG (table 1). Mucosal hyperproliferation is linked to apoptosis, and there is mounting evidence that $H$ pylori induces apoptosis. ${ }^{58} 59$ The bcl-2 proto-oncogen is involved in controlling apoptosis and is related to the initial phase of cancer. ${ }^{6061}$ The expression of the bcl-2 gene was unaltered in our patients with chronic gastritis, regardless of $H$ pylori infection, which supports the idea that $H$ pylori induced apoptosis occurs through a mechanism that is independent of bcl-2 gene expression. ${ }^{62} \mathrm{bcl}-2$ gene expression was also preserved in our patients with early gastric cancer, but was undetectable in advanced cancer. This finding contrasts with reports of bcl-2 overexpression in intestinal type gastric cancer. ${ }^{37}{ }^{38}$ It is conceivable that the discrepancy is related to differences in populations studied and in the type, staging, and grading of cancer.

A chronic hyperproliferative state may also favour cellular DNA damage. ${ }^{37-22} 2425$ We detected a relation between chronic hyperproliferation and cellular DNA damage only in $H$ pylori positive patients with active gastritis. Therefore the cytotoxic effect of $H$ pylori infection and the related polymorphonuclear leucocyte infiltration may play important roles in the development and progression of mucosal damage. Aberrant DNA is a prognostic indicator for cancer ${ }^{49}{ }^{63-65}$ and seems to be independent of other clinical pathological factors. ${ }^{66}$ We detected aneuploidy in all our cancer patients, but we also identified a novel subset of pCG patients with aneuploidy (11/53) (table 3). Aneuploidy was significantly associated with c-Myc and/or p53 expression (fig 1 and table 4 ), which are the most widely used markers of genomic instability.

The c-Myc oncogene is implicated in the transformation and progression of mutated cells. ${ }^{67-69}$ In this study it was expressed in 36\% of gastric cancer $(4 / 11)$ and $15 \%$ of pCG $(8 / 53)$ patients. This is a novel finding because the expression of $\mathrm{c}-\mathrm{Myc}$ has not previously been investigated in chronic gastritis or in relation to $H$ pylori status. c-Myc expression is more frequent in gastric adenocarcinoma than in adenoma and has also been proposed as an aid to differentiate between the two conditions. ${ }^{39}$ Half of the patients with c-Myc expression and aneuploidy had p53 overexpression, which was also detected in $63 \%$ of gastric cancer patients. The mutation of the p53 gene, which we found in $15 \%$ of pCG patients, is a common occurrence in colorectal carcinoma where it is related to a poor prognosis and distant metastasis. ${ }^{30-32}$ It has been reported in gastric cancer ${ }^{34} 35$ and precancerous gastric lesions ${ }^{36}$ but never in relation to $H$ pylori infection.

Interestingly, aneuploidy and c-Myc and p53 expression were not detected in the absence of $H$ pylori contamination or in patients with $H$ pylori infection but without gastric atrophy. Therefore, in our population, the appearance of genomic instability required the presence of both gastric atrophy and chronic $H$ pylori infection (fig 1).
Several studies have shown that patients with preneoplastic and neoplastic gastric epithelial lesions are more likely to be infected by CagA positive strains ${ }^{70-74}$ which possess a genomic insertion called "cag pathogenicity island" which includes genes involved in virulence. ${ }^{41}$ Infection by CagA positive $H$ pylori strains increases the risk of developing atrophy and intestinal metaplasia possibly because of the enhanced inflammatory potential shown by these strains. ${ }^{70-73}$ Although investigated only in about $50 \%$ of pCG patients, the high prevalence of positivity for CagA (23 of 25 subjects studied) may help to explain the high incidence of atrophy (49\%) and intestinal metaplasia (34\%) observed in our patients. Furthermore, the enhanced prevalence of DNA aneuploidy and p53 and c-Myc expression in our patients is in agreement with the observation of an increased cancer risk in individuals infected by CagA positive $H$ pylori strains compared with individuals infected by Cag negative $H$ pylori strains $^{74}$ and, more in general, in individuals who live in areas with a high rate of CagA positive $H$ pylori strains. ${ }^{70}$ Unfortunately, we were not able to verify this hypothesis directly because of the small number of CagA negative patients in this study.

The effects of $H$ pylori eradication on atrophy and related intestinal metaplasia are controversial and there is no consensus among gastrointestinal pathologists as to the identification and grading of these lesions. In a recent study, no changes in intestinal metaplasia and atrophy were detected after $H$ pylori eradication irrespective of $H$ pylori CagA status. ${ }^{9}$ In contrast, we found that $H$ pylori eradication may be followed, one year after treatment, by the disappearance of complete metaplasia and/or reduction of atrophy (table 5), when both are present in the antrum. Other groups have reported similar results. ${ }^{11}{ }^{12}$ The patchy nature of the lesions and the subjective nature of the interpretation may account for these controversial findings. ${ }^{75}$ However, according to a recent stringent definition of atrophy, "true irreversible" atrophy is differentiated from "apparent" atrophy which is reversed by removal of inflammation. ${ }^{77}$ Our finding of disappearance or regression of atrophy, mainly from the antrum, after $H$ pylori eradication suggests that inflammatory infiltration plays a role in this controversial histological finding, even though we cannot rule out the involvement of other factors such as age, sex, diet, genetic makeup of the host, nature of the lesions, biopsy sampling, $H$ pylori strains, and environmental toxic factors. Long term studies and a larger number of stratified patients in relation to age of infection are needed to establish definitely the reversibility of $H$ pylori related lesions and the predictive value of genetic markers for $H$ pylori eradication.

Our data confirm the significant link between such precancerous features as incomplete metaplasia and dysplasia and genomic instability. However, we found genomic instability in four cases not showing these morphological aspects (fig 1). It is noteworthy that in Barrett's oesophagus, p53 overexpression 
precedes dysplasia in patients followed for about three years. ${ }^{78} 79$

In conclusion, chronic $H$ pylori infection seems to be responsible for genomic instability in a subset of cases of $H$ pylori positive chronic atrophic gastritis and also in the absence of notorious precancerous lesions like metaplasia and dysplasia; eradication of $\mathrm{H}$ pylori infection can reverse inflammation and related atrophy, metaplasia, and genomic instability. Finally, we suggest that pCG patients with atrophy should receive eradication treatment for $H$ pylori, while pCG patients with $H$ pylori infection who do not respond to antibiotic treatment should be examined for markers of genomic instability and closely monitored.

We would like to thank Rosa Napolano and Antonella Coppeto for help and assistance with endoscopy and biopsy specimens and we are indebted to Jean Gilder for editing and revising the
text. Preliminary data from this study were presented at the text. Preliminary data from this study were presented at the 10-16 May, 1997. This research was supported by a grant from MURST (40 and 60\%) Rome, Italy.

1 IARC Working Group on the Evaluation of Carcinogenic Risks to Humans. Helicobacter pylori. In: Schistosomes, liver flukes, and Helicobacter pylori: views and expert opinions of an IARC Working Group on the Evaluation of Carcinogenic Risk to Humans. Lyon: IARC, 1994:177-240.

2 Cover TL, Blaser MJ. Helicobacter pylori: a bacterial cause of gastritis, peptic ulcer disease and gastric cancer. American Society of Microbiology News 1995;61:21-6.

3 Correa P. Helicobacter pylori and gastric carcinogenesis. Am $\mathcal{F}$ Surg Pathol 1995;19:S37-43.

4 Correa P. The gastric precancerous process. Cancer Surg 1993;2:437-50.

5 Correa P. Human gastric carcinogenesis: a multistep and multifactorial process. First American Cancer Society Award Lecture on Cancer Epidemiology and Prevention. Cancer Res 1992;52:6735-40.

6 Rugge M, Cassaro M, Leandro G, et al. Helicobacter pylori in promotion of gastric carcinogenesis. Dig Dis Sci in promotion

7 Kuipers EJ, Perez-Perez GI, Meuwissen SGM, et al. Helicobacter pylori and atrophic gastritis: importance of the CagA status. F Natl Cancer Inst 1995;87:1777-80.

8 Correa P, Miller MJS. Helicobacter pylori and gastric atrophy. Cancer paradoxes. F Natl Cancer Inst 1995;87:1731-2.

9 Van Der Hulst RWM, Van Der Ende A, Dekker FW, et al. Effect of Helicobacter pylori eradication on gastritis in relation to CagA: a prospective 1-year follow-up study. Gastroenterology 1997;113:25-30.

10 Fossati D, Alvisi C, Frego R, et al. No change in intestinal metaplasia after $\mathrm{H}$ pylori eradication [abstract]. Gut 1996; 39(suppl 2):A104

11 Griffiths AE, Thursz MR, Walker MM. Do intestinal metaplasia and gastric atrophy reverse after $\mathrm{H}$ pylori eradication plasia and gastric atrophy reverse after H
[abstract]? Gut 1996;39(suppl 2):A48-9.

12 Pasztorova I, Chinyama C, Filipe MI, et al. Regression of gastric intestinal metaplasia after eradication of Helicobacter pylori: a prospective study [abstract]. Gut 1996; 39(suppl 2):A55.

13 Bishop JM. Cancer: the rise of the genetic paradigm. Genes Dev 1995;9:1309-15.

14 Levine DS, Rabinovitch PS, Haggitt RC, et al. Distribution of aneuploid cell populations in ulcerative colitis with dysplasia or cancer. Gastroenterology 1991;101:1198-210.

15 Nardone G, D'Armiento F, Corso G, et al. Lipids of human gastric mucosa: effect of Helicobacter pylori infection and non alcoholic cirrhosis. Gastroenterology 1994;107:362-8.

16 Mauch F, Bode G, Ditschuneit H, et al. Demonstration of a phospholipid-rich zone in the human gastric epithelium damaged by Helicobacter pylori. Gastroenterology 1993; 105:1698-704.

17 Lynch DAF, Mapstone NP, Clarke AMT, et al. Cell proliferation in Helicobacter pylori associated gastritis and the effect of eradication therapy. Gut 1995;36:346-50.

18 Lynch DAF, Mapstone NP, Clarke AMT, et al. Cell proliferation in the gastric corpus in Helicobacter pylori associated gastritis and after gastric resection. Gut 1995;36 351-3.

19 Brenes F, Ruiz B, Correa P, et al. Helicobacter pylori causes hyperproliferation of the gastric epithelium: pre- and posteradication indices of proliferating cell nuclear antigen. $A m$ f Gastroenterol 1993;88:1870-5.

20 Fox JG, Xiantang LI, Rachel JC, et al. Hypertrophic gastropathy in Helicobacter felis-infected wild-type C57BL/ 6 mice and p53 homozygous transgenic mice. Gastroenterology 1996;110:155-66.

21 Correa P, Ruiz B, Shi TY, et al. Helicobacter pylori and nucleolar organizer regions in the gastric antral mucosa. Am F Clin Pathol 1994;101:656-60.
22 Panella C, Ierardi E, Polimeno L, et al. Proliferative activity of gastric epithelium in progressive stages of Helicobacter pylori infection. Dig Dis Sci 1996;41:1132-8.

23 Allen A, Flemstrom G, Garner A, et al. Gastroduodenal mucosa protection. Physiol Rev 1993;73:823-57.

24 Medline A, Farber E. The multi-step theory of neoplasia. In: Anthony PP, Sweeney RNM, eds. Recent advances in histopathology, no 11. Edinburgh: Churchill Livingstone, 1981:19-34.

25 Yabuki N, Sasano H, Tobita M, et al. Analysis of cell damage and proliferation in Helicobacter pylori-infected human gastric mucosa from patients with gastric adenocarcinoma. Am F Pathol 1997;151:821-9.

26 Carneiro F, David L, Sobrinho-Simoes M, et al. Oncogenes and onco-suppressor genes in gastric carcinoma. Surg Pathol 1994:5:225-38.

27 Enoch T, Norbury C. Cellular responses to DNA damage: cell-cycle checkpoints, apoptosis and roles of p53 and ATM. Trends Biochem Sci 1995;20:426-30.

28 Lane DP. p53, guardian of the genome. Nature 1992;358: 15-16.

29 Levine AJ, Momand J, Finlay CA. The p53 tumour suppressor gene. Nature 1991;351:453-6.

30 Mulder JWR, Wielenga VJM, Polak MM, et al. Expression of mutant p53 protein and CD 44 variant proteins in colorectal tumorigenesis. Gut 1995;36:76-80.

31 Kawasaki Y, Monden T, Morimoto H, et al. Immunohistochemical study of p53 expression in microwave-fixed, paraffin-embedded sections of colorectal carcinoma and adenoma. Am f Clin Pathol 1992;97:244-7.

32 Campo E, de la Calle-Martin O, Miquel R, et al. Loss of heterozygosity of $\mathrm{p} 53$ protein expression in human colorectal carcinomas. Cancer Res 1991;51:4436-42.

33 Burmer GC, Rabinovitch PS, Haggit RC, et al. Neoplastic progression in ulcerative colitis: histology, DNA content, and loss of a 53 allele. Gastroenterology 1992;103:1602-10.

34 Starzynska T, Bromley M, Ghosh A, et al. Prognostic significance of $\mathrm{p} 53$ overexpression in gastric and colorectal carcinoma. Br f Cancer 1992;66:558-62.

35 Hurlimann J, Saraga EP. Expression of p53 protein in gastric carcinomas. Am f Surg Pathol 1994;18:1247-53.

36 Craanen ME, Blok P, Dekker W, et al. Chronology of p53 protein accumulation in gastric carcinogenesis. Gut 1995; 36:848-52.

37 Lauwers GY, Scott GV, Karpeh MS. Immunohistochemical evaluation of bcl-2 protein expression in gastric adenocarcinomas. Cancer 1995;75:2209-13.

38 Bronner MP, Culin C, Reed JC, et al. The $\mathrm{bcl}_{2}$ protooncogene and the gastrointestinal epithelial tumor progression model. Am 7 Pathol 1995;146:20-6.

39 Tatsuta $M$, Iishi $\mathrm{H}$, Baba $M$, et al. Expression of c-myc mRNA as an aid in histologic differentiation of adenoma from well differentiated adenocarcinoma in the stomach. Cancer 1994;73:1795-9.

40 The European Helicobacter pylori study group. Current European concepts in the management of Helicobacter pylori infection. The Maastricht Consensus Report. Gut 1997;41:8-13.

41 Censini S, Lange C, Xiang Z, et al. Cag, a pathogenicity island of Helicobacter pylori, encodes type I-specific and
disease-associated virulence factors. Proc Natl Accad Sci USA 1996;93:14648-53.

42 Dixon MF, Genta RM, Yardley JH, et al. Classification and grading of gastritis. Am f Surg Pathol 1996;20:1161-81.

43 Hsu SM, Raine L, Faine L, et al. Use of avidin-biotinperoxidase complex (ABC) in immunoperoxidase technique: a comparison between $\mathrm{ABC}$ and unlabeled antibody (PAP) procedures. F Histochem Cytochem 1981;29: $577-80$

44 Egan MJ, Freeth M, Crocker J. Intraepithelial neoplasia, human papillomavirus infection and argirophylic nucleoproteins in cervical epithelium. Histopathology 1988;13: $561-7$

45 Crocker J, Nar P. Nucleolar organizer regions in lymphomas. F Pathol 1987;151:11-18.

46 Gonzalez AP, Kumar D, Sanchez RL. AgNOR area measurements differentiate benign and malignant melanocytic lesions more accurately than simple counting. $A m \mathcal{f}$ Dermatopathol 1994;16:372-6.

47 Crocker J, Boldi DAR, Egan MJ. How should we count AgNOR? Proposal for a standardized approach. $\mathcal{F}$ Pathol 1990;158:185-8.

48 Bocking A, Adler CP, Common $\mathrm{HH}$, et al. Logarithm for a DNA-photocytometric diagnosis and grading of malignancy. Anal Quant Cytol Histol 1984;6:1-8.

49 Marrero JM, de Caestecker JS, Corbishley CM, et al. Gastric DNA content in postgastrectomy patients. Cancer 1996;77:19-24.

50 Laemmli UK. Cleavage of structural proteins during the assembly of the head of bacteriophage T4. Nature 1970;227:680-5.

51 Biasco G, Paganelli GM, Miglioli M. Cell proliferation biomarkers in the gastrointestinal tract. $f$ Cell Biochem 1992; (suppl 16G):73-8

52 Cahill RJ, Kilgallen C, Beattil S, et al. Gastric epithelial cell kinetic in the progression from normal mucosa to gastric carcinoma. Gut 1996;38:177-81.

53 Tsujii M, Kawano S, Tsuji S, et al. Ammonia: a possible promotor in Helicobacter pylori-related gastric carcinogenesis. Cancer Lett 1992;65:15-18.

54 Megraud F, Neman-Simha V, Brugmann D. Further evidence of the toxic effect of ammonia produced by Helicobacter pylori urease on human epithelial cells. Infect Immun 1992;60:1858-63. 
55 Murakami M, Asagoe K, Dekigai H, et al. Products of neutrophil metabolism increase ammonia-induced gastric
mucosal damage. Dig Dis Sci 1995;40:268-73.

56 Fraser AG, Sim R, Sankey EA, et al. Effect of eradication of Helicobacter pylori on gastric epithelial cell proliferation. Aliment Pharmacol Ther 1994;8:167-73.

57 Chow KW, Bank S, Ahn J, et al. Helicobacter pylori infection does not increase gastric antrum mucosal cell proliferation. Am $\mathcal{F}$ Gastroenterol 1995;90:64-6.

58 Moss SF, Calam J, Agarwal B, et al. Induction of gastric epithelial apoptosis by Helicobacter pylori. Gut 1996;38:498501

59 Peek RM, Kerr LD, Miller GG, et al. H pylori induces apoptosis in gastric epithelial cells by an NFK-Bindependent mechanism [abstract]. Gut 1997;41(suppl 1):A45.

60 Hockenbery DM, Nunez G, Milliman C, et al. Bcl-2 is an inner mitochondrial membrane protein that blocks proinner mitochondrial membrane protein that

61 Reed JC. Bcl-2 and the regulation of programmed cell death. F Cell Biol 1993;124:1-6.

62 Chen G, Sordillo EM, Ramey WG, et al. Apoptosis in gastric epithelial cells is induced by Helicobacter pylori and accompanied by increased expression of BAK. Biochem Biophys Res Commun 1997;239:626-32

63 Ohyama S, Yonemura Y, Miyazaki I. Prognostic value of S-phase fraction and DNA ploidy studied with in vivo administration of bromodeoxyuridine on human gastric cancers. Cancer 1990;65:116-21.

64 Sugihara H, Hattori T, Fujita S, et al. Regional ploidy variations in signet ring cell carcinomas of the stomach. Cancer 1990;65:122-9.

65 Kitayama Y, Nakamura S, Sugimura H, et al. Cytophotometric and flow cytometric DNA content of isolated glands in gastric neoplasia. Gut 1995;36:516-21.

66 Flyger HL, Christensen IJ, Thorup J, et al. DNA aneuploidy in gastric carcinoma. Scand $\mathcal{F}$ Gastroenterol 1995;30:258-64.

67 Vaux DL, Cory S, Adams JM. Bcl-2 gene promotes haemopoietic cell survival and cooperates with c-myc to poietic cell survival and cooperates with c-m
immortalize pre-B cells. Nature 1988;335:440-2.
68 Bissonnette RP, Echeverri F, Mahboubi A, et al. Apoptotic cell death induced by c-myc is inhibited by bcl-2. Nature 1992;359:552-4.

69 Fanidi A, Harrington EA, Evan GI. Cooperative interaction between c-myc and bcl-2 proto-oncogenes. Nature 1992; 359:554-6.

70 Blaser MJ, Perez-Perez GI, Kleanthous H, et al. Infection with Helicobacter pylori strains possessing CagA is associated with an increased risk of developing adenocarcinoma of the stomach. Cancer Res 1995;55:2111-15.

71 Figura N, Bugnoli M, Cusi MG, et al. Pathogenic mechanisms of Helicobacter pylori: production of cytotoxin. In: Malfertheiner P, Ditschuneit H, eds. Helicobacter pylori, gastritis and peptic ulcer. Berlin, Heidelberg: SpringerVerlag, 1990:86-95.

72 Kuipers EJ, Perez-Perez GI, Meuwwissen SGM, et al. Helicobacter pylori and atrophic gastritis: importance of the CagA status. F Natl Cancer Inst 1995;87:1777-80.

73 Sozzi M, Valentini M, Figura N, et al. Atrophic gastritis and intestinal metaplasia in Helicobacter pylori infection: the role of CagA status. Am f Gastroenterol 1998;93:375-9.

74 Parsonnet J, Friedman GD, Oremtreich N, et al. Risk for gastric cancer in people with CagA positive or CagA negative Helicobacter pylori infection. Gut 1997;40:297-301.

75 Reid BJ, Haggitt RC, Rubin CE, et al. Observer variation in the diagnosis of dysplasia in Barrett's esophagus. Hum Pathol 1988;19:166-78.

76 Dixon MF, Brown LJR, Gilmour HM, et al. Observer variation in the assessment of dysplasia in ulcerative colitis. Histopathology 1988;13:367-84.

77 Genta RM. Helicobacter pylori, inflammation, mucosal damage and apoptosis: pathogenesis and definition of gastric atrophy. Gastroenterology 1997;133:S51-5.

78 Levine DS. Barrett's oesophagus and p53. Lancet 1994;344: 212-13.

79 Younes S, Lebovitz M, Lechago LV, et al. p53 protein accumulation in Barrett's metaplasia, dysplasia and carcinoma: a follow-up study. Gastroenterology 1993;105:1637-42. 